\title{
TRAUMATIC ATLANTO-AXIAL FRACTURE DISLOCATION IN A CHILD
}

\author{
CASE REPORT \\ T. McSwEEney, M.Ch.(N.U.I.), M.Ch.(Orth.), F.R.C.S.(Eng.) \\ The Robert Fones and Agnes Hunt Orthopaedic Hospital, \\ Oswestry, Shropshire, U.K.
}

\begin{abstract}
An I8-month-old child was rendered tetraplegic below C6 in a road traffic accident. There was an associated fracture-dislocation of the atlanto-axial joint. Early management, and the probable role of autonomic dysreflexia in increasing the neurological deficit are considered.
\end{abstract}

Key words: Atlanto-axial dislocation; Spinal cord injury; Encephalopathy; Dysreflexia.

\section{Case Report}

L. D. an I8-month-old girl was transferred from another hospital 2 days after a high velocity road traffic accident in which her father and brother were killed. She was sitting in a child's safety seat at the time of impact and secured with lap and shoulder harness.

When seen in the Accident Unit the head was observed to be rotated to the right with the chin resting on the chest. There were no marks about the head and neck but the abrasion marks caused by the harness were clearly visible across the front of the chest. A complete motor and sensory paralysis below C6 was noted. X-rays showed a displaced fracture of the odontoid process with forward dislocation of the atlanto-axial joint (Fig. I). There was no evidence of a bony injury at the appropriate level or elsewhere in the spine. The dislocation was easily reduced without anaesthesia and a collar applied (Fig. 2).

The previous findings were confirmed on admission to the Spinal Injury Unit at Oswestry. The routine nursing care was continued and intermittent catheterisation instituted. The child was extremely apprehensive, the dislocation was not controlled by the collar and routine turns caused great pain. For these reasons and a reluctance to use calipers on thin skull bone an open reduction was undertaken. The procedure was carried out under X-ray control with fixation of the atlas to the axis using a braided wire suture (Fig. 3).

The postoperative course was uneventful and automatic micturition was established during the third week. She was sat out of bed in a wheel chair during the sixth week. There had been no change in the neurological picture-the lesion remained complete below C6. A sheepskin lined plaster jacket as developed by Draycott (1973) proved helpful at this stage. Before discharge from hospital she was able to 'walk' using a Shrewsbury Splint (Fig. 4).

After discharge from the Spinal Injury Unit she continued to make good progress, but I 8 months later was admitted unconscious to the Paediatric Unit at another hospital. A few hours earlier she had developed clonic movements of the upper limbs with jerking and hypertonicity more marked on the left side. The pupils were equal and reacted to light in the normal way. There was no sign of increased intracranial pressure as evidenced by examination of the fundi. Lumbar puncture showed a clear fluid under normal pressure and with normal analysis. Over the next few hours the clinical situation resembled that of status epilepticus which slowly responded to various anticonvulsant 


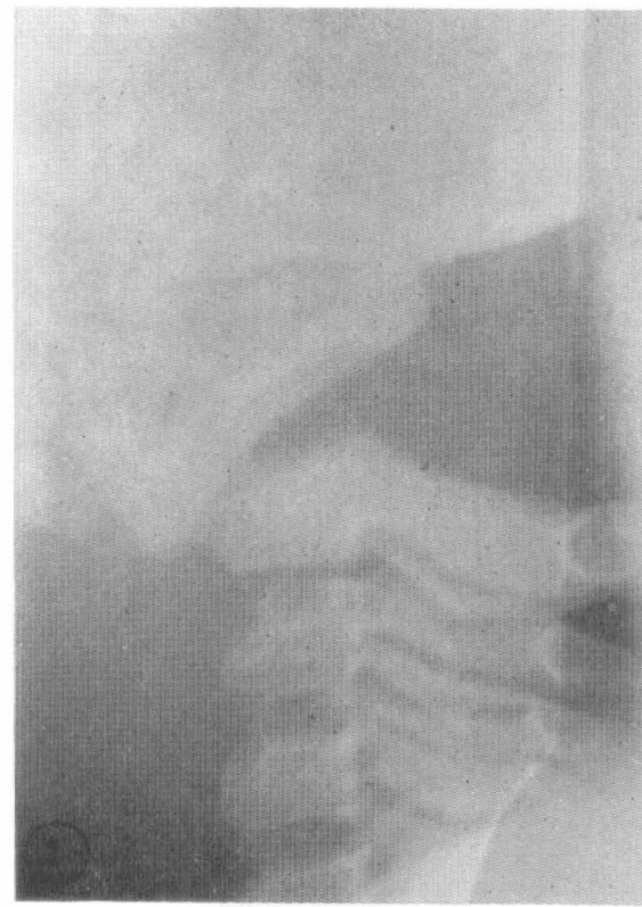

FIG. I

Fracture of odontoid process with atlanto-axial dislocation.

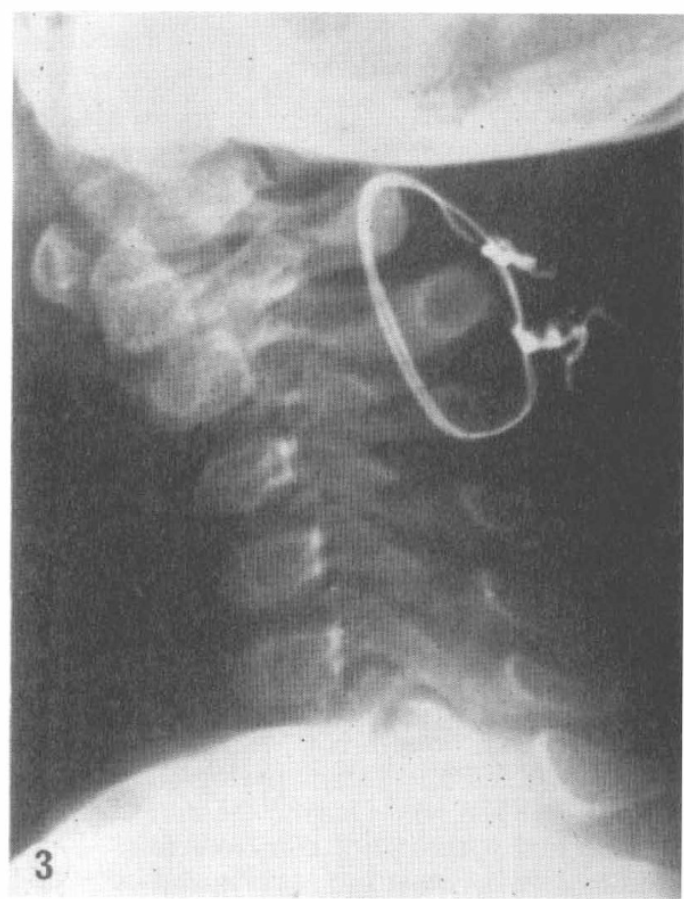

FIG. 3

Dislocation reduced and fixed with braided wire suture.

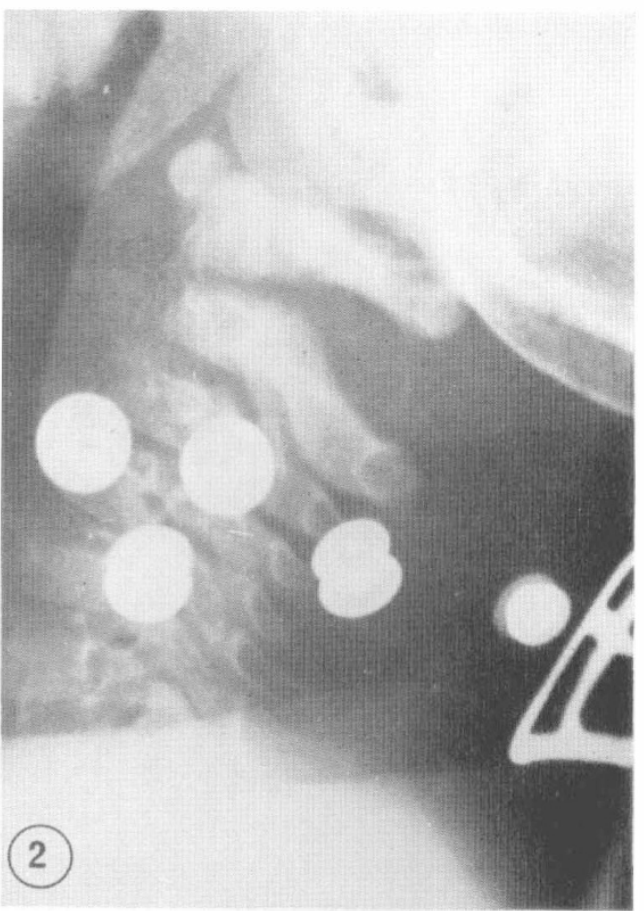

FIG. 2

Dislocation reduced in a collar.

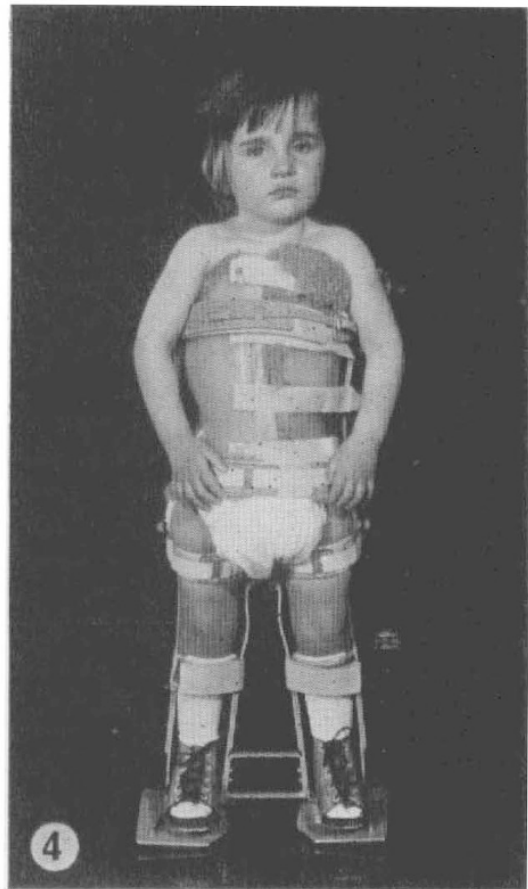

FIG. 4 Shrewsbury swivel walker. 


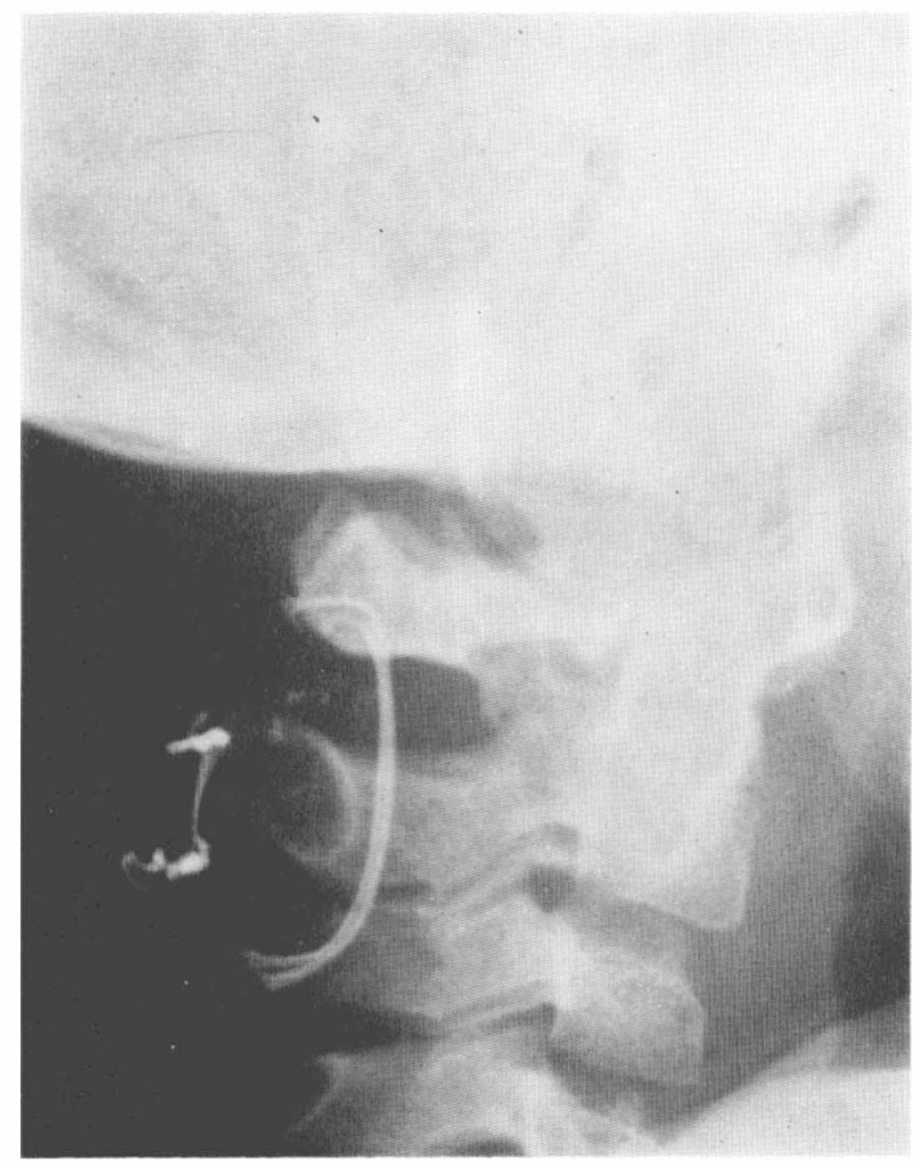

FIG. 5

Odontoid fracture soundly healed. No atlanto axial instability.

drugs. The fits continued for many weeks. A brain scan was normal. Electro-encepholograms were grossly abnormal, and were reported to have affected the right cerebral hemisphere more than the left. Before discharge from the Paediatric Department she had regained the ability to elevate the shoulder girdles and abduct the right arm. The right biceps was improving, but she could not flex the left elbow. There was a partial left-sided facial palsy. The previous flaccid paralysis of the lower limbs was changing to a spastic one.

The patient remains under out-patient supervision at the Spinal Injury Unit. She attends school and appears to be a bright, happy child, well adjusted to a wheelchair life. She is no longer able to use the swivel walker. The tetraplegia remains complete below C6. There is a flexion contracture of the left elbow and only a flicker of voluntary contraction in the left biceps. The deep tendon reflexes are brisker on the left side, and the plantar responses are extensor. The facial palsy is no longer evident. The resting systolic blood pressure is I IO $\mathrm{mm} \mathrm{Hg}$ and the diastolic $70 \mathrm{~mm} \mathrm{Hg}$. A satisfactory threehourly pattern of automatic micturition is maintained and recent pyelograms are satisfactory. The odontoid fracture is soundly healed (Fig. 5). Despite the anti-convulsant therapy she is still subject to minor fits associated with loss of consciousness. During these episodes the mean blood pressure readings are between $150 \mathrm{~mm} \mathrm{Hg}$ and $90 \mathrm{~mm} \mathrm{Hg}$. 
Expression of the bladder is usually but not invariably followed by a rapid decline in blood pressure.

\section{Discussion}

Spinal cord injuries in children are uncommon. The subject has been reviewed by Melzak (1969), Burke (1976), Hacken (1977) and Renard et al. (1978). Bony or ligamentous injury to the spinal column is seldom demonstrable. In this case the bony injury was probably caused by deceleration forces leading to ventro flexion of the head on the cervical spine. The bony injury was not directly associated with the spinal cord lesion and the former might be regarded as an incidental finding. It may be postulated that the neurological damage resulted from a 'stretch injury' of the spinal cord, following the changes in the relative lengths of the spinal canal and the spinal cord. This can occur in extreme ventro flexion of the entire axial skeleton (Breig, 1960) but seems unlikely in the present case because the safety harness remained intact. A more appealing explanation is that the combined effect of momentum and the loss of continuity at the atlantoaxial level resulted in pathological axial traction on the spinal cord.

Surgical intervention was considered to be justified for reasons already mentioned. Two points are worth mentioning. Radiological confirmation of reduction at the time of operation is essential. A small right-angled aneurysm needle is a convenient instrument to carry the suture deep to the arch of atlas. There were some misgivings as to the effects of internal fixation on the growing spine. Growth has not been materially effected possibly because of breakage of the wire suture sometime during the sixth post operative month.

The Shrewsbury splint had been very successful until the onset of the convulsions and the subsequent assymetrical increase in the paralysis. The splint is based on the swivel-plate principle introduced by McLaurin and modified by Rose for patients with severe neurological disorders (Rose, I970). Bipedal gait is achieved by transfer of energy from the shoulder girdles to the foot plates. The earlier models (Rose \& Henshaw, 1972 and 1973) have been updated and are available in kit form (Stallard et al., I978).

The cause of the convulsions is still a mystery. The most likely explanation is a rise in blood pressure because of autonomic hyperreflexia (Head \& Riddock, I9I 7; Guttmann \& Whitteridge, I947; Bors \& Blinn, I957). It may be significant that on the night before the first fit the child had returned from holidays and is reputed to have had a mild urinary tract infection. The 'status epilepticus' may have been mistaken for hypertensive encephalopathy. A dramatic rise in blood pressure leading to a right-sided cerebral haemorrhage would neatly explain the upper motor neurone lesion on the opposite side. The resulting scar tissue may explain the later development of an eleptogenic focus. While there was some return of muscle tone in the lower limbs and in the axial muscles of the trunk within 6 months of the initial injury, the plantar responses were equivocal and there was no enhancement of the deep tendon reflexes. The sensory loss appeared complete and all the indications were those of a total cord lesion. Following the episode of 'encephalopathy' there has been a gradual increase in spasticity in the lower limbs which raises the question of how complete is the neural damage here, or has there been some regeneration of the long tracts. On subsequent admissions to the Spinal Unit a correlation between the rise in blood pressure and the state of the bladder has been noted. This is a matter which merits further investigation.

Less dramatic episodes of hypertension still occur despite the present pattern of automatic voiding, and the fact that all concerned have been instructed in the 
dangers of allowing the bladder to over-distend. Is there a place for urological surgery here? Will progressive spinal deformity require major surgery (McSweeney, 1976), and are fits inevitable because of the presumed cerebral scarring? These and many other questions remain unanswered.

\section{SUMMARY}

The present case illustrates some of the problems of spinal cord injuries in young children. The possibility of autonomic dysreflexia should be considered when there are any unusual manifestations. Monitoring of the blood pressure is advised.

\section{RÉSUMÉ}

La présentation de ce cas souligne quelques uns des problèmes qui existent dans les tetraplégies infantiles traumatiques. En présence de signes cliniques inhabituels, il faut penser à une manifestation de dysréflexie autonome. Il est recommandé de mesurer la tension artérielle.

\section{ZUSAMMENFASSUNG}

Dieser Fall zeigt einige der Probleme, die bei kleinen Kindern mit einer Rückenmarkverletzung vorkommen können. Wenn aussergerichtliche Situation nen vorliegen, sollte man an die Möglichkeit einer autonomischen Dysreflexic denken. Deshalb sollte man den Bludruck überwachen.

\section{REFERENCES}

Bors, E. \& Blinn, K. A. (I957. Spinal reflex activity from the vesical mucosa in paraplegic patients. Archs Neurol. Psychiat., 78, 339-354.

BURKE, D. C. (1976). Injuries of the spinal cord in children. In Handbook of Clinical Neurology, vol. 25. Injuries of the Spine and Spinal Cord, Part I, pp. I75-I95. P. J. Vinken \& G. M. Bruyn (eds.). North Holland Publishing Co., Amsterdam.

BREIG, A. (I960). Biomechanics of the Central Nervous System. Alamqyist and Wiksells, Uppsala.

DraycotT, V. (1973). Spina bifida splint. Brit. Med. F., I, 743.

GutTMANN, L. \& WhitTERIDGE, D. (I947). Effects of bladder distension on autonomic mechanisms after spinal cord injury. Brain, 70, 36I-405.

HACKEN, H. J. (1977). Spinal injury in children and adolescents: diagnostic pitfalls and therapeutic considerations in the acute stage. Paraplegia, 15, 55-64.

HEAD, H. \& RidDOCK, G. (I9I7). The automatic bladder, excessive sweating and some other reflex conditions in gross injuries of the spinal cord. Brain, 40, I88-263.

MCSwEENEY, T. (I976). Deformities of the spine following injuries to the cord. In Handbook of Clinical Neurology, vol. 26. Injuries of the Spine and Spinal Cord, Part II, P. J. Vinken \& G. H. Bruyn (eds.), pp. 159-I84. North Holland Publishing Co., Amsterdam.

MelzaK, J. (1969). Paraplegia among Children, Lancet, 2, 45-48.

Renard, M., Tridon, P., Kuhaust, M., Renauld, J. M. \& Dolfuss, P. (I978). Three unusual cases of spinal cord injury in childhood. Paraplegia, 16, I30-134.

Rose, G. K. (1970). Splintage for severe spina bifida cystica. F. Bone and foint Surg., 52, B.I, I78-I79.

Rose, G. K. \& Henshaw, J. T. (1972). A swivel walker for paraplegics: medical and technical considerations. Biomed. Eng., 7, 9, 420-425.

Rose, G. K. \& Henshaw, J. T. (I963). Swivel walkers for paraplegics: considerations and problems in their design and application. Bull. Pros. Res., B.D.R. IO-20, 62-74.

Stallard, J., Rose, G. K. \& Farmer, I. R. (I978). The Orlau Swivel Walker. Prosthetics and Orthotics International, 2I, 43-47. 